\title{
Redes clientelares, agentes y dependientes en el espacio señorial castellano. Dinámica de articulación de linajes y elementos para su análisis.
}

\section{Client networks, agents and dependents in the Castilian manorial space. Lineage dynamics and elements for its analysis}

\author{
Osvaldo Víctor Pereyra \\ Centro de Historia Argentina y Americana, Instituto de Investigaciones en Humanidades y \\ Ciencias Sociales, Consejo Nacional de Investigaciones Científicas y Técnicas, Universidad \\ Nacional de La Plata, Argentina. \\ vopereyra@gmail.com
}

\section{Resumen}

En el presente trabajo se realiza una observación del fenómeno señorial de expansión patrimonial y político de la Casa de los Velasco, desde un punto de vista "integral", es decir, focalizando el análisis no sólo en el proceso de engrandecimiento del linaje sino también desde "abajo", poniendo énfasis en la propia dinámica de articulación con los linajes menores asentados en los espacios locales y comarcales sujetos al poder jurisdiccional y a su presencia señorial. Se analizará la densificación señorial impuesta por la presencia de los Velasco en la ZONA ORIENTAL de Cantabria (englobando en ella la antigua MERINDAD DE VECIO y los valles de TRASMIERA) a partir del estudio de la red de relaciones matrimoniales y clientelares sostenidas con los linajes menores asentados en estos espacios.

Palabras claves: linaje; bandos linajes; agentes señoriales; red de relaciones matrimoniales.

Abstract 
In the present work an observation is made of the manorial phenomenon of patrimonial and political expansion of the House of the Velasco, from an "integral" point of view, that is, focusing the analysis not only on the process of aggrandizement of the lineage but also from "below", emphasizing the very dynamics of articulation with minor lineages established in local and regional spaces subject to jurisdictional power and their stately presence. It will be analyzed the seigniorial densification imposed by the presence of the Velasco in the ORIENTAL ZONE of Cantabria (including the old MERINDAD DE VECIO and the valleys of TRASMIERA) from the study of the network of matrimonial and clientelist relations sustained with the minor lineages settled in these spaces.

Keywords: lineages; lineage group; stately agents; marriage relationship network.

1. El objetivo del presente artículo es realizar una observación analítico-metodológica del fenómeno señorial desde un punto de vista integral, es decir, focalizando el análisis no sólo en el proceso de engrandecimiento de un linaje castellano -la Casa de los Velasco, Condestables hereditarios del Reino de Castilla- sino también desde abajo, poniendo énfasis en la propia dinámica de articulación con los linajes menores asentados en los espacios locales y comarcales que se encuentran sujetos al poder jurisdiccional y a su presencia señorial. Analizar la densificación señorial a partir de los cambios que impone la presencia de los Velasco en la Zona Oriental de Cantabria (englobando en ella la antigua Merindad de Vecio y los valles de Trasmiera) a partir del estudio de la red de relaciones matrimoniales y clientelares constituidas con los linajes menores asentados en estos espacios septentrionales del reino de Castilla desde el siglo XIV al XVI. (Figura 1)

Figura 1: Zona Oriental (Merindad de Vecio (1) y Trasmiera)

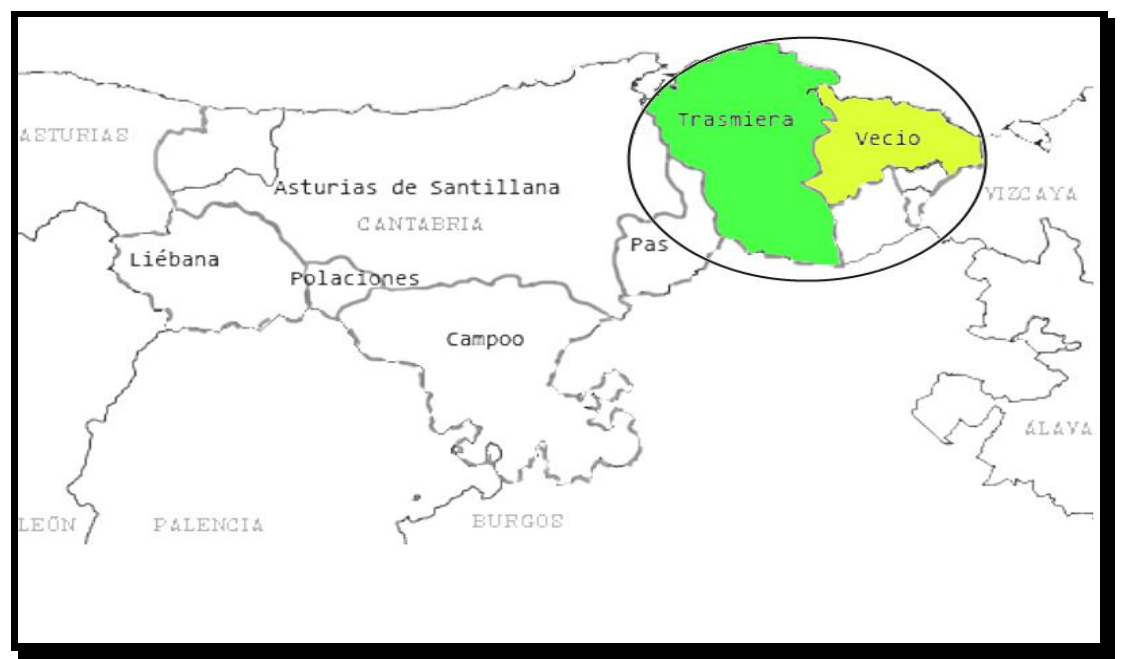

Mapa de elaboración propia 
Para intentar reconstruir el entramado vincular entre el señor y estos vasallos ubicados al interior de las comunidades locales jerarquizadas es necesario definir una unidad de análisis que homologue e inscriba el conjunto plural de grupos y familias de poder que forman parte de estas villas y aldeas e interconectan el conjunto complejo de la red señorial. Esta investigación recurre -como unidad de análisis- al linaje, partiendo de la idea de que en este tipo de sociedades no se puede entender al actor social, sus estrategias, así como las diversas relaciones que establece, tomando al mismo como un sujeto carente de raíces. La familia, el linaje, el grupo, su estirpe, su casa:(2) son los espacios de significaciones que le otorgan existencia y que determinan su lugar dentro de un entramado profundamente jerarquizado, que dota de sentido a todas sus acciones. Estamos en presencia de una sociedad corporativa donde el actor social es un colectivo, un grupo de personas portadoras de una misma función y estatuto, y fuera del cual no existe el individuo.

Estos linajes se nos presentan como laestructura básica de organización familiarque dota de coherencia a los grupos más prósperos e influyentes de la sociedad cántabrovizcaína desde la baja Edad Media. Consistentes en un grupo de descendencia patrilineal, unido por lazos de parentesco (natural o artificial) entre sus miembros, integraba en su seno tanto a padres, hijos y parientes cercanos, así como también a distintos grupos familiares que conformaban sus clientelas componiendo, en torno al pariente mayor o el cabeza de linaje, diversos círculos de dependencia y lealtad. (Figura 2).

Figura 2: Esquema de múltiples relaciones centradas en la figura del Pariente Mayor

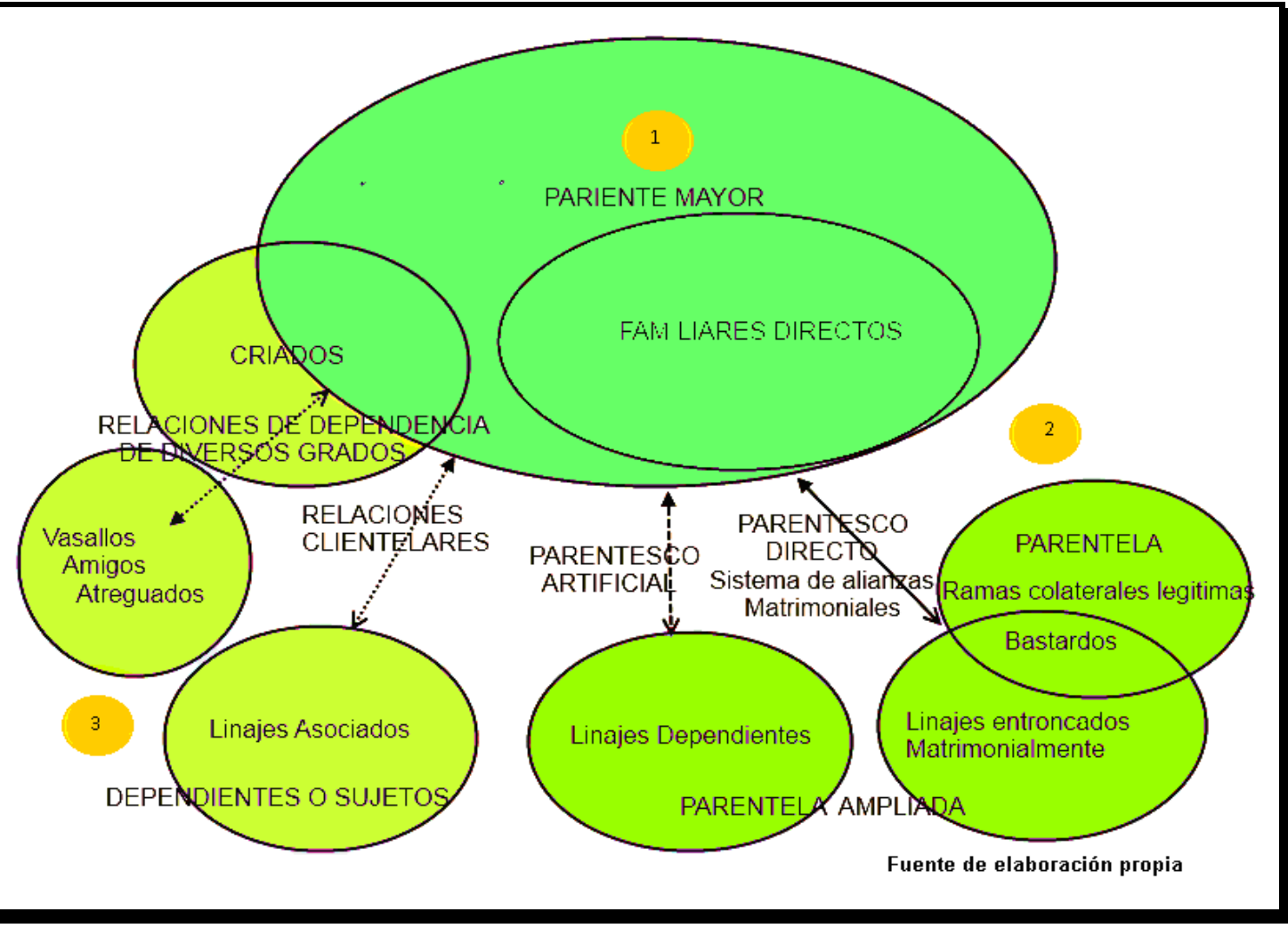


Los fines principales que sustentan estas estructuras parentales amplias son la defensa y acrecentamiento del patrimonio familiar, así como la promoción e influencia social y política de sus miembros en el plano local / regional o comarcal.

Analíticamente, el linaje se presentaba como una configuración asociativa de enorme flexibilidad, pudiendo establecer alianzas más dilatadas que terminaban conformando en estos espacios septentrionales los llamados bandos linajesy bandos parcialidades movilizados en función de su dependencia a su cabeza política que son los parientes mayores. En la densificación que adquieren estas coaliciones amplias de linajes desempeñan un papel fundamental las mujeres, a través del conjunto de las alianzas matrimoniales generadas endogámicamente por estos grupos de poder.

Los linajes son así el centro estructurado del conjunto de relaciones parentales y clientelares que articulan el espacio social y político que ocupan estos grupos dominantes. Partimos de estas células organizativas primarias para analizar el desarrollo, configuración y articulación que adquieren los grupos dominantes a nivel local. La estabilidad de dichas configuraciones asociativas de poder primarias deviene del hecho de que las mismas reproducían sobre el conjunto valores de solidaridad y cohesión entre sus miembros que se encontraban así unidos a un patronímicocomún que les permitía distinguirse del resto de la población. De esta manera, dichas estructuras linajísticas se nos aparecen establecidas con un fuerte componenteterritorial y económico, ya que, al mismo tiempo, eran el instrumento mediante el cual los grupos dominantes garantizaban la apropiación de sus recursos.

El problema para el historiador simplemente radica en cómo ordenar la compleja panoplia de elementos que la documentación procedente del área cántabro-vizcaína se asocia con la idea de linaje: parentela / vasallos / amigos / atreguados / encomendados, encartados, etc. Es decir, elementos que se encuentran unidos por relaciones de parentesco real y consanguíneo, así como aquellos vinculados por pseudo-parentesco o relaciones de parentesco artificial, hasta grupos familiares unidos por diversas relaciones de dependencia personal y políticas con el cabeza de linaje.

\section{En búsqueda de un ordenamiento: topo-linajes / solar y la centralidad de los relatos genealógicos.}

Entre los debates historiográficos actuales se encuentra abierta la cuestión de la intrincada relación existente entre Historia y Memoria. Dos registros diferentes, aunque tengan un mismo fundamento genético, el pasado, o si se prefiere una forma particular de la reconstrucción del mismo. Sin ánimo de polemizar sobre el problema que presenta para los historiadores esta particular forma de recuperación narrativa es posible admitir que la 
misma cumple funciones de legitimación, didácticas y propagandísticas generales que, en distintos tiempos y sociedades, la convierten en un importante elemento a historiar.(3)

El relato genealógico se nos impone como un importante elemento "ordenador" para analizar una sociedad septentrional bajo medieval que se nos presenta compleja y variada, tanto en los valles y aldeas que conforman su paisaje rural como así también en las numerosas villas del interior y de la costa que configuran su tímido e incipiente sistema urbano. Una sociedad donde se nos aparece un amplio abanico de tipos sociales que van desde los labradores -término genérico que designa en la documentación al campesino parcelario sometido a censo- a los mercaderesexportadores -sectores enriquecidos por el monopolio en la explotación del hierro y el comercio marítimo- pero, compartiendo todos ellos, una condición jurídico-social bastante extendida: la hidalguía.

Paralelamente -pese a su fuerte componente estamental- se nos presenta como una sociedad en movimiento, sometida a intensos cambios producto de la puja distributiva de la renta feudal entre los principales linajes hidalgos agrupados en formas amplias de asociación denominadas bandos linajes y parcialidades.(4) La violencia generalizada causada por estos enfrentamientos tiene un alcance global y una extensión temporal espectacular -de más de un siglo-(5) que permean la vida cotidiana de estas poblaciones sujetas a la lucha fratricida, impulsados por las relaciones de fidelidad y obediencia hacia los dictados políticos impuestos por los llamados parientes mayores(6) a quienes, según García de Salazar, se los "catavan todos por mayor".(7)

El Libro de bienandanzas e fortunas constituye un ejemplo más dentro de un vasto repertorio de obras que componen un género extenso de literatura genealógica 0 , simplemente, nobiliario diseminados en todo el conjunto de los reinos bajo medievales del occidente europeo. A fines del siglo $\mathrm{XI}(8)$ este tipo de literatura comienza a tener desarrollo debido a los intereses de las casas nobiliarias por fundamentar sus aspiraciones políticas. (9) Siguiendo la periodización propuesta hace unos años por I. Beceiro Pita,(10) se puede afirmar que entre la segunda mitad del siglo XIV y mediados del siglo XVI, con la consolidación paulatina del sistema de linaje -basado en la primacía de la primogenitura masculina en la trasmisión de la herencia que devendrá finalmente en su formalización jurídica a través del mayorazgo-(11) tenemos también el florecimiento de este tipo de narrativa en el espacio peninsular al calor del fortalecimiento de la nobleza y el incremento paulatino de sus derechos.

Pero ¿de qué tipo de linajes estamos hablando? Como es común en este tipo de literatura encontramos que en las Bienandanzas e fortunas el sentido familiar y patrimonial de la nobleza se encuentra inextricablemente unido.

Tan estrecha es la unión entre topos y linaje que en muchas ocasiones es imposible distinguir si el nombre del lugar deviene del apellido o, inversamente, es el locativo el que se define a partir del mismo. Dicha unión de sentidos se encuentra en la base de lo que $A$. 
Guerreau-Jalabert, idea retomada posteriormente por J. Morsel, puntualiza como topolinaje. Dicha conceptualización permite, a nuestro juicio, reflejar la mixtura feudal entre el espacio y el parentesco lo que determinará, como principio la conformación de la síntesis entre tierra y familia, el solar. Los topo-linajes no necesariamente constituyen linajes -en el sentido estricto patrilineal del término- sino estructuras más o menos formalizadas, más o menos abiertas, centradas en la trasmisión de la herencia sin que indefectiblemente la misma deba ser sostenida por el hijo varón -aunque puede ser señalada ésta como preferencia- ya que a falta del mismo en la línea sucesoria es posible que las mujeres, o ramas secundarias o un hijo bastardo configuren alternativas válidas a las cuales echar mano ante la ausencia de heredero legítimo.

Estamos así en presencia de un elemento bastante plástico y maleable que determina el sentido poli-funcional que adquiere la narrativa y la construcción de la memoria genealógica, no sólo un simple "registro" parental, sino una necesaria apropiación hereditaria de los honores con la voluntad de fijar los límites a posibles concurrentes estableciendo, a partir de la memoria, la legitimación del poder. Dicho de otro modo, si bien estas formas de relato genealógico asumen una dinámica centrada en las relaciones de parentesco ello no debe hacernos olvidar que las mismas se encuentran supeditadas y subordinadas a la lógica señorial imperante de las que nacen y a las cuales sirven de justificativo.

El desafío consiste en establecer un relato genealógico como las Bienandanzas e fortunas como un punto de llegada en la evolución de la noción de linaje, ubicándonos así en la propia definición amplia que les otorga García de Salazar: "de dónde suçedieron e suçeden de unos en otros...".(12) De esta manera, estamos en presencia de la propia utilidad con la que fue diseñada este tipo de narrativa, tendiente a legitimar la definición de un sistema particular de filiación descendente preferentemente agnaticio -frente al cognaticio que imperaba en los primeros siglos medievales- donde sobresale la masculinidad, pero también tiene un lugar fundamental la primogenitura. (Figura 3)

Figura 3: Diagrama de desarrollo y articulación inter-linajísticas/articulación socio-espacial. 


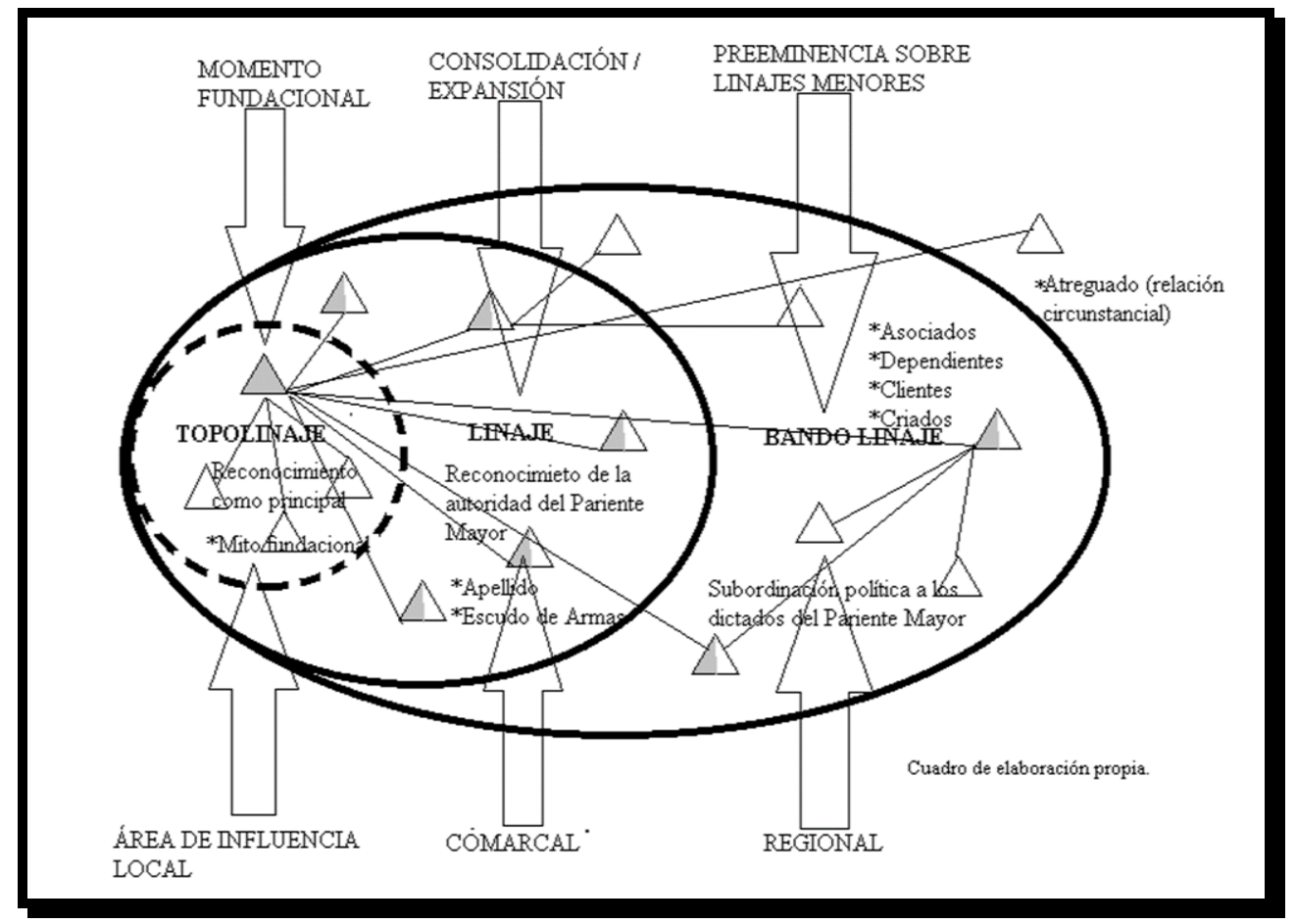

\section{Del uso de información deslindada de fuentes fiscales}

Si tomamos el Libro Becerro de las Behetrías,(13) como fuente para el estudio del poder feudal castellanoes posible acercarnos a la geografía señorial que presenta la Merindad de Castilla la Vieja hacia mediados del siglo XIV.

Sin duda, dicha entidad administrativo-política es la más compleja y extensa de las Merindades descriptas por la pesquisa cubriendo, aproximadamente, un total de 4.360 $\mathrm{km}^{2}$, repartidos entre las actuales provincias de Logroño, Álava, Cantabria y Burgos. Circunscribiendo, a su interior, un total de 534 lugares, que se encuentran desigualmente repartidos. Como nuestro interés radica en el análisis de las redes señoriales -más allá del espacio fiscal que el mismo deslinda- lo que nos resulta sugestivo es el hecho de que en este dilatado territorio se plasma un conjunto heterogéneo de espacios señoriales que delimitan diversas percepciones de rentas y derechos. Hay que agregar el hecho de que en cada lugar podemos encontrar, al mismo tiempo, una diversidad de formas de extracción rentística donde pueden ser señalados simultáneamente más de un propietario feudal, por lo que no es posible sostener una imagen rígida y simplista que identifique directamente a cada lugar con un señor. (Figura 4).

Figura 4: Lugares y tipo de señores señalados por el libro Becerro. 


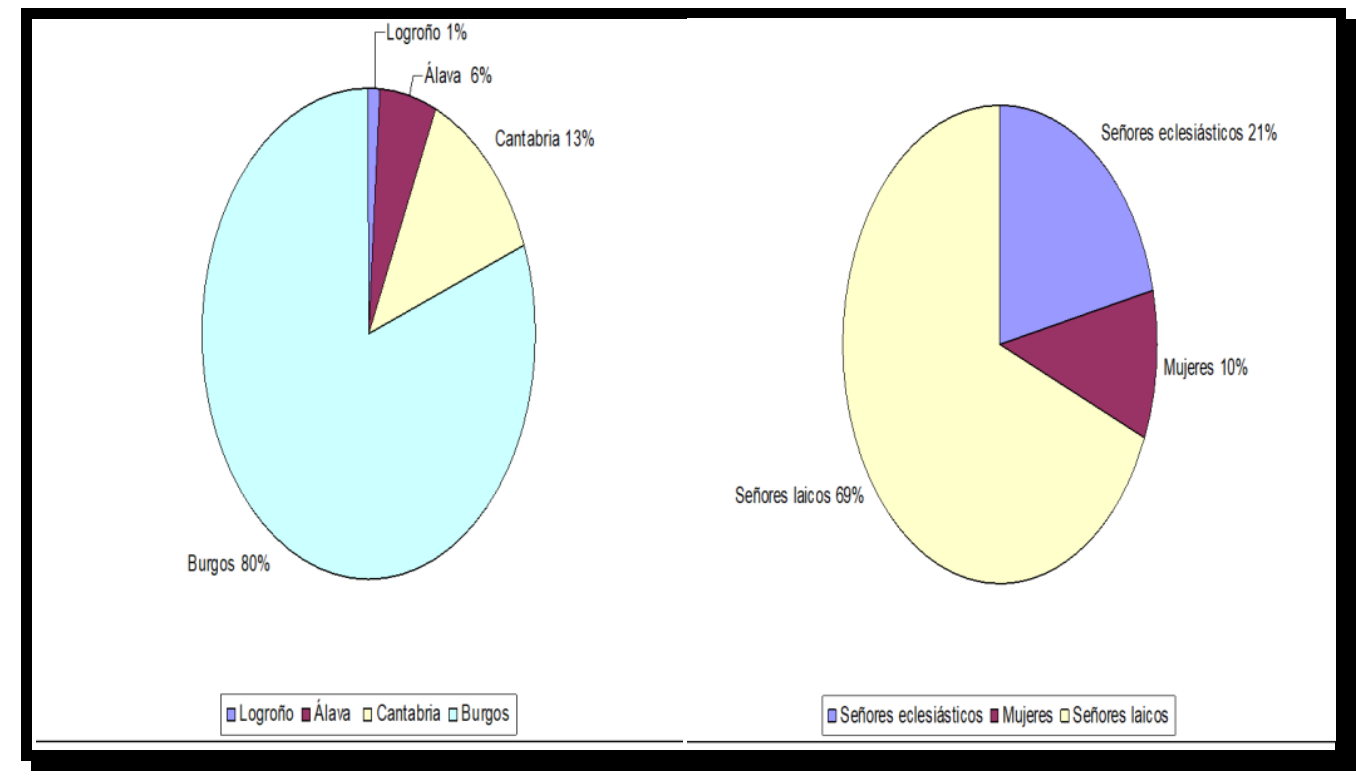

Empezando por el área septentrional de Cantabria, la que involucra la costa cantábrica y el valle de Trasmiera, el apellido de los Agüero aparece profusamente señalado en El libro Becerro con más de sesenta y dos menciones, cubriendo, algo más de treinta y cinco lugares. Constituye, sin duda, el linaje trasmerano más importante hasta la llegada de los Velasco, ya que los mismos figuran como antiguos "parientes mayores" que ostentaron la dirección del bando de los Negretes, opuestos al bando de los Giles dirigido por otro importante linaje señorial cántabro, los Solórzano, hasta mediados del siglo XV, momento en el cual pasaron a ocupar la dirección del bando adversario.(14) Giles y Negretes eran por entonces las etiquetas generales que terminaron involucrado al conjunto de los linajes menores que vemos actuar en el espacio trasmerano.

Hacia mediados del siglo XIV, las posesiones señoriales de los Agüero se extendían por todo el conjunto de las juntas trasmeranas. Su presencia señorial aparece registrada sobre el amplio territorio, figurando en algunas localidades, como poseedor de solariego exclusivo, otras de solariego compartido con otros señores laicos o con el Rey (como en el caso de Orejo), o como señor y natural de behetría.

De esta manera encontramos que el linaje de los Solórzano se hallaba firmemente instalado en la Junta de Cestos y Voto (Trasmiera) en donde parece actuar como linaje local principal hasta el advenimiento de los Agüero, compitiendo espacialmente con ellos en el desarrollo de su ámbito señorial llegando, incluso, a ser señalados los Solórzano como parientes mayores tanto del bando de los Giles como también del bando de los Negretes.

Dicha articulación de bandos se extendía desde el río Nervión hasta la zona vizcaína y guipuzcoana enlazando estos linajes de origen cántabro con los que vemos actuar profusamente en País Vasco: los llamados Gamboínos, eran afectos a los Giles, mientras los Oñacinos apoyaban, por oposición, a los Negretes. Bajo esta denominación amplia de 
Giles y Negretes parecen articularse todo el conjunto de linajes menores pertenecientes a estos territorios cantábricos, aún aquellos autóctonos que habían logrado su ascenso a través de su participación en las rentas producidas en el espacio rural y en las actividades comerciales de la zona costera. Es interesante señalar la mención que hace el cronista banderizo de estos linajes vernáculos menores acerca de que "no son Giles ni Negretes por natura" y que pueden desarrollarse gracias al "paraguas" y la protección del solar de los Agüero.Dicho dato no es menor. Se nos presenta como parte esencial de la dinámica propia que adquiere el sistema de bandos linajes que reconocen, jerárquicamente, el liderazgo del "pariente mayor" en la dirección de los mismos. Tanto Agüeros como Solórzano se atribuían así las direcciones políticas de ambas banderías y sobre ellos también gira -según el autor de las Bienandanzas y Fortunas- el origen mismo de las desavenencias y disputas en la región. (Figura 5).

Figura 5: Linaje de los Agüero Linaje de los Solórzano

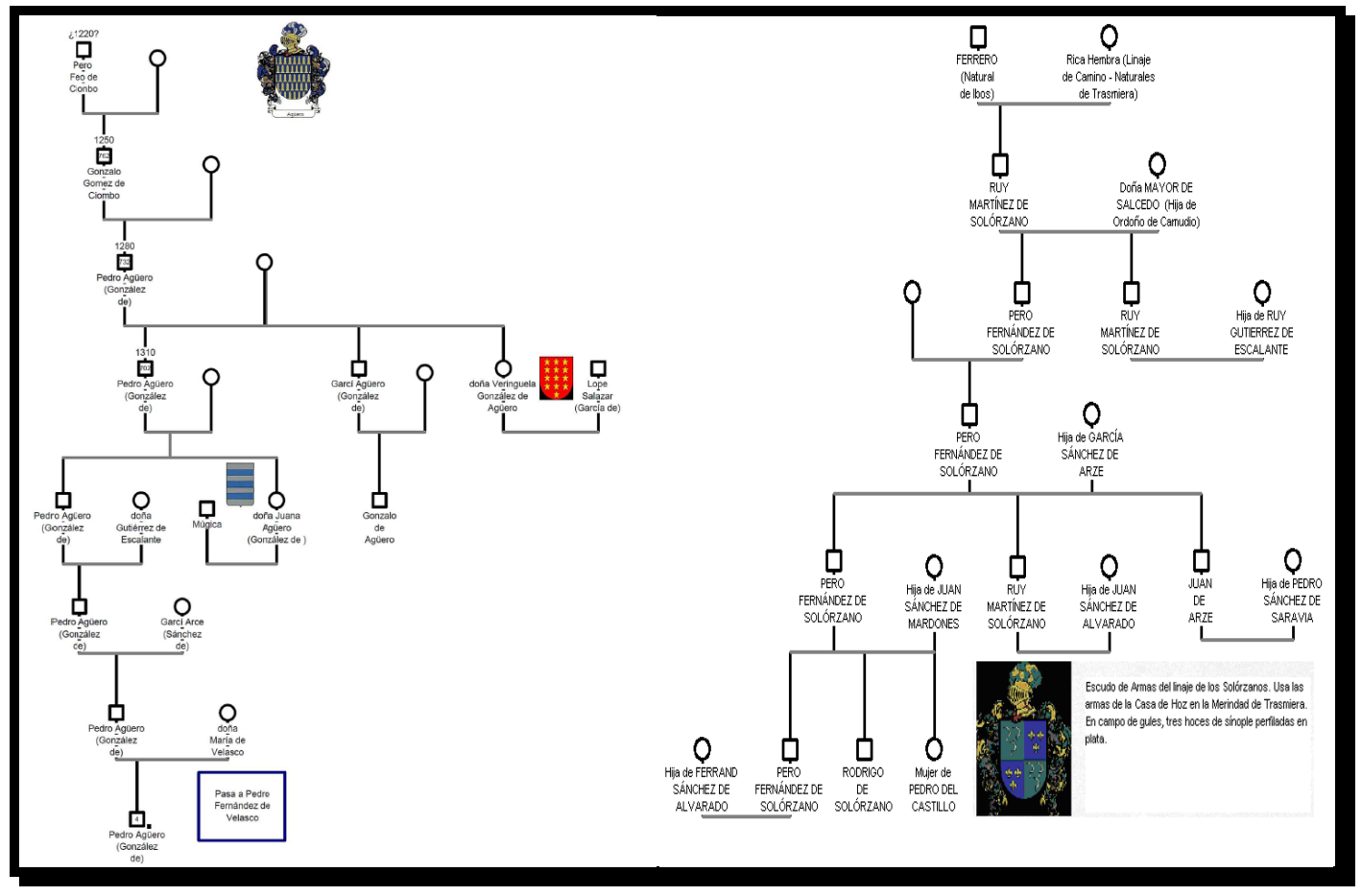

El asentamiento territorial de los intereses señoriales de los Velasco en los espacios cantábricos alterará los precarios equilibrios alcanzados por los linajes comarcales y locales agrupados en los distintos bandos linajes de los Giles y los Negretes, y terminará modificando también las relaciones de poder a nivel de las distintas comunidades locales.

Este fenómeno presenta, si se quiere, una doble direccionalidad que es importante resaltar: por un lado, a través de la dinámica de confrontación banderizada, los Velasco toman partido y utilizan su posición de superioridad para asentar su poder e intereses económicos sobre el territorio trasmerano rompiendo con las articulaciones previas alcanzadas a nivel local por estos linajes que se presentan como rivales. Por otro lado, 
dichas alianzas constituyen una base de promoción y crecimiento para estos caballeros de linajes de proyección regional. (Es el caso del entronque matrimonial entre don Pedro Fernández de Solórzano y doña María Fernández de Velasco y Sarmiento. El mismo enlace constituye, sin dudas, una base firme de promoción del linaje de los Solórzano al unirse con una representante de una casa noble castellana en ascenso y que, a su vez, relaciona su apellido con la llamada antigua nobleza, como es el caso de los Sarmiento. Sin embargo, estas alianzas matrimoniales conllevan también peligros a estos linajes menores, la lógica expansiva y fagocitaria impulsada por los representantes de la alta nobleza como los Velasco pueden llevar también, como en el caso de los Agüero, a la extinción de los estos linajes dependientes menores.)

\section{De las alianzas matrimoniales como punto convergente de los análisis en la reconstrucción reticular}

El matrimonio no era el resultado de una decisión personal sino un instrumento de acuerdos que alcanzaban al conjunto parental amplio. Los matrimonios fueron utilizados por los linajes en atención a una estrategia centrada en la acumulación tanto de capital simbólico (honor) como de capital político y económico (dinero y propiedades) y, la mejor manera de proteger y acrecentar los mismos era, por consiguiente, asegurar que el cónyuge sea socialmente un igual. De esta manera, la mujer se convertía en una prenda dentro de las estrategias de reproducción de los linajes. Por ende, estas situaciones de reforzamiento de alianzas no eran un escenario accidental en el contexto de la lucha de bandos sino todo lo contrario, una forma normal y extendida de vinculación que reforzaba la conexión entre los mismos.

A partir de la importancia medular que adquieren estas relaciones de intercambio matrimonial para los efectivos humanos ceñidos en torno a los linajes es posible avanzar en la visualización de las complejas estructuras clientelares que articulaban estos espacios de señorialización. Para ello hemos combinado, a partir de los datos de los cuadros genealógicos anteriormente presentados, en una matriz única de análisis de redes (programa PAJEK) donde hemos podido graficar el conjunto de relaciones entre los vértices (representantes individuales de los linajes mencionados) en una matriz compuesta, que, posteriormente hemos energizado a través del algoritmo de FruchtermanReingold. Este algoritmo actúa como un mecanismo de repulsión alejando los nodos más aislados y acercando los más conectados. Esta característica le permite visualizar de forma más clara las sub-redes que componen la red. Para su representación, hemos optado por sustituir los nombres por la ubicación numérica en la tabla de los individuos consignados en las tablas genealógicas anteriores con el fin de facilitar la visualización de la matriz misma. (Figura 6). 


\section{Figura 6: Matriz de interrelaciones matrimoniales//Matriz potenciada (Fruchterman-Reingold)}

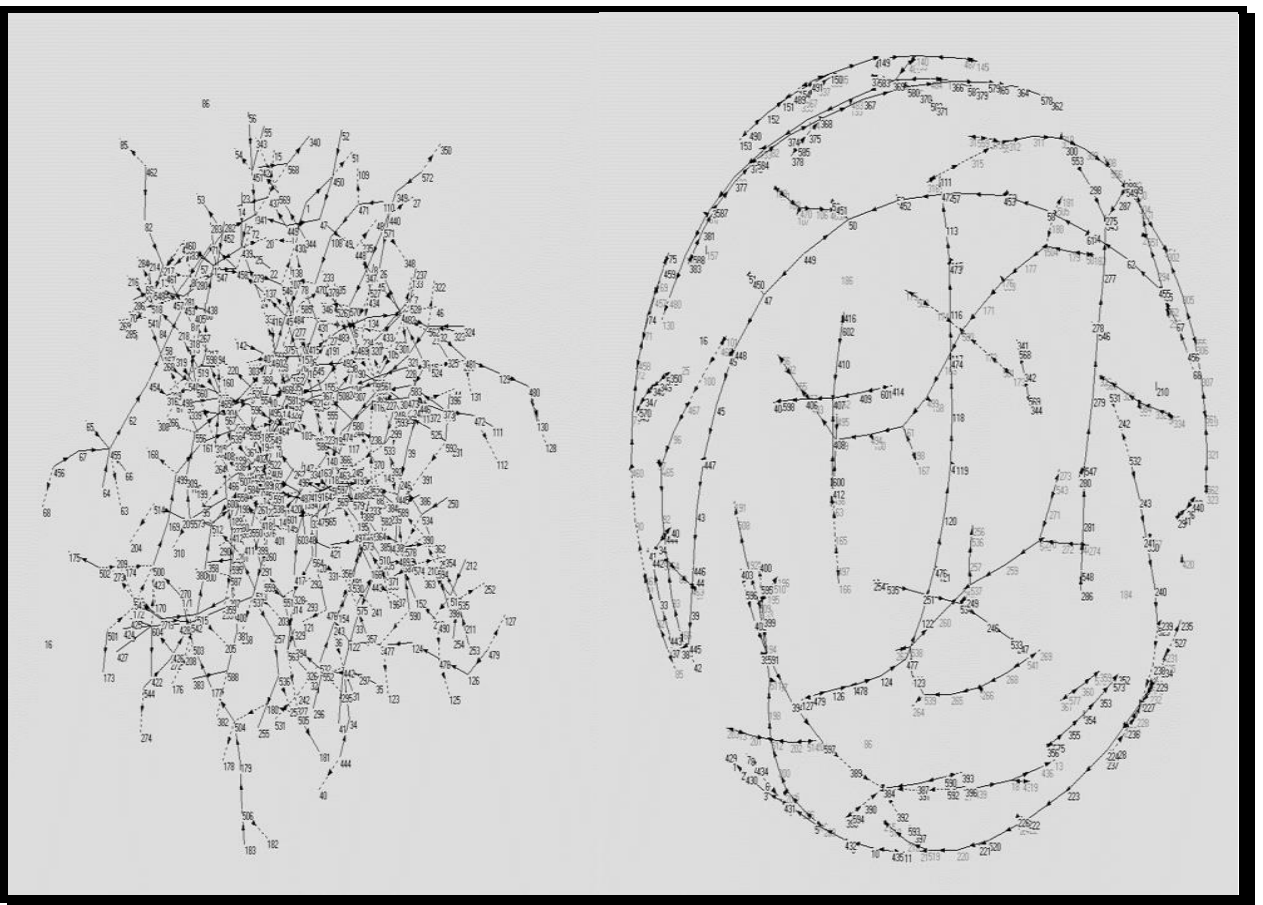

El análisis de redes, nuestra matriz de relaciones matrimoniales inter-señoriales, parte de la convención de que los actores o nodos se encuentran conectados y la representación gráfica de la misma consta de los tres elementos esenciales que establece la composición de toda red: nodos o actores, sus vínculos y la direccionalidad de los flujos. El tamaño de la matriz se corresponde con el número total de actores consignados ( $\Sigma$ total de individuos de las tablas genealógicas) que representan un total de 604 nodos, con sus respectivas relaciones (unidireccionales, multidireccionales o ninguna) otorgando un total de 8.955 vinculaciones ponderables que definen el patrón observado en la matriz, proporcionándonos una forma simplificada y sintética de analizar la estructura de una red.

El conjunto de vínculos entre los nodos es el punto esencial de la red que constituye justamente eso, un sistema complejo de vínculos. Es por ello que la ubicación de los nodos no es aleatoria, su lugar corresponde a la ponderación aritmética del grado de articulación, siendo más alto en su centro que en los bordes, por lo que, claramente, al estar basado nuestro sociograma en el conjunto de relaciones matrimoniales impulsadas por los linajes, la representación gráfica del mismo nos muestra una tendencia a la concentración globular, lo que nos permite visualizar una tendencia media a la articulación con una baja cantidad de conexiones sueltas (o de vínculo débil) con personas de fuera de la red principal (ejemplos nodos 16 y 86). La densidad de la red está en el orden de la media de $2,4587 \%$, lo que teóricamente da por resultado una red socio-céntrica positiva de baja densidad.

Lo argumentado se grafica mejor en la matriz energizada a través del algoritmo de Fruchterman-Reingold, donde podemos apreciar el grado de separación de los grafos 
independientes (ubicados en el contorno) y sus conectores, grafos que unen los espacios de separación entre los distintos puntos de la esfera. Ello se correlaciona con el hecho de la existencia de ciertos linajes que sirven de articuladores al interior de todo el conjunto. Apellidos como los Agüero, Alvarado, Amoros, Castillo, Carasa, Escalante, Marroquín, Mioño, Muñatones, Otañes, Salazar, Solórzano, Velasco, etc., figuran como nodos múltiples interconectaras, es decir, con mayor capacidad de interrelación. (Figura 7).

Figura 7: Informe matriz (programa GENOPRO)

- A: 9 Familias, 65 individuos: Agüero (30) Alvarado (15) Amorós (8) Anuavay (4) Arce (4) Asturias (1) Avellaneda (1) Avendaño (1) Alvear (1)

- B: 3 Familias, 6 individuos: Bear (4) Bracamonte (1) Butrón (1)

- C: $\mathbf{1 4}$ Familias, $\mathbf{6 4}$ individuos Castillo (35) Carasa (8) Corrilla (4) Cariaga (3) Cardo (2) Ciombo (2) Calderón (2) Calleja (1) Camino (1) Campos (1) Castañeda (1) Cavalla (1) Ceballos (1) Córdoba (1)

- E: 1 Familia, 6 individuos Escalante (6)

- F: $\mathbf{2}$ Familias, $\mathbf{2}$ individuos Fernández (1) Ferrero (1)

- G: 4 Familias, $\mathbf{5}$ individuos Gebaja (2) Godos (1) González (1) Gordejuela (1)

- H: 3 Familias, 4 individuos Hoyos (3) Haro (1) Haedo (1)

- I: 1 Familia, 2 individuos Iseca (2)

- L: 2 Familias, 2 individuos Lacavez (1) Leguizamón (1)
- M: 11 Familias, 64 individuos Marroquín (28) Mioño (16) Muñatones (6) Marrón (5) Matra (3) Macos (1) Mardones (1) Mena (1) Moro (1) Mugica (1) Murga (1)

- O: 3 Familias, 24 individuos Otañes (12) Obra (11) Ortíz (1)

- P: 5 Familias, 14 individuos Puente (7) Piedra (4) Pelegrín (1) Porres (1) Portugalete (1)

- R: $\mathbf{5}$ Familias, $\mathbf{1 1}$ individuos Redondo (6) Rada (2) Rodríguez (1) Roiz (1) Rojas (1) S: 9 Familias, 85 individuos Salazar (48) Solórzano (17) Saravia (7) Salcedo (5) Sámano (2) Sánchez (2) Secadura (2) Sandoval Santamaría (1)

- T: 4 Familias, $\mathbf{4}$ individuos Tenorio (1) Terreros (1) Tobar (1) Turcios (1)

- $\mathrm{V}: \mathbf{1 0}$ Familias, $\mathbf{4 8}$ individuos Velasco (30) Villota (5) Venero (5) Valmaseda (2) Varacaldo (1) Varado (1) Vasurto (1) Velas de Rada (1) Vergones (1) Villarías (1)

- Z: 1 Familia, 1 individuo Zevallos (1)

Lo importante de rescatar aquí es el hecho de que estos apellidos, que actúan como interconectares generales, muestran claramente que los mismos manifiestan un alto grado de centralidad al interior de la red. Se puede observar cómo estos apellidos actúan multiplicando las interconexiones y dándole densidad al tejido señorial. Claro ejemplo de ello es el hecho de que los mismos conectan puntos opuestos dentro de la dispersión radial, lo que nos habla de la importancia que adquiere el fenómeno de entroncamiento matrimonial en la articulación de la misma.

La cohesión es una de las características que le brinda a un grupo mayores ventajas, tanto en estructura como en funcionalidad, le permite alcanzar sus metas más rápida y satisfactoriamente. Ahora bien, para determinar la cohesión grupal, es necesario explorar la relación de la red con sus componentes. Existe poca cohesión entre los subgrupos y el grupo total, de allí la importancia que adquieren estos apellidos que sirven como interconectores, ellos suplen la baja atracción hacia el grupo. Ellos consignan las 
distancias más cortas (the shortest line) de 0, 00587, siendo las más largas (the longest line) 0,13442, centrándose, las mismas, en los linajes menores. Se comprueba así la existencia de una dispersión en las relaciones intra e inter grupales con la existencia de subgrupos bien definidos.

Son estas configuraciones de linaje principales las que, basadas en una política matrimonial extendida, terminarán interconectando los distintos subgrupos linajísticos locales, emparentándolos, tanto a través de su tronco principal y ramas secundarias, como incluso por medio de efectivos humanos bastardos, reforzando con ello el grado de cohesión que presenta la matriz señorial en su conjunto. Sobre esta urdimbre de relaciones inter-linajísticas participan, de manera destacada, los Velasco; primero como un linaje menor de proyección comarcal y, posteriormente, como linaje principal y pariente mayor, afectando, con ello, las primigenias articulaciones.

\section{Algunas conclusiones teórico-metodológicas}

He intentado presentar, en esta apretada síntesis, un modelo de análisis relacional ARS-SNA(15) centrado en las interconexiones entre linajes mayores y menores en el espacio oriental cántabro-vizcaíno en la temprana modernidad. Un estudio que podemos definir como de articulación socio-territorial. Es posible, ahora, componer algunas conclusiones teórico-metodológicas al respecto:

$\checkmark$ Desde un punto eminentemente abstracto las redes son polimorfas -de allí su utilidad funcional en cualquier tipo de investigación sociohistórica- pueden contener diversos elementos (personas, grupos, instituciones, colectivos más o menos formalizados, etc.) consignar a su interior diferentes vínculos (comerciales, conocimiento, estatus, influencia, afinidad, enemistad, poder, violencia, clientelismo, alianza, filiación, consanguinidad, parentesco ficticio, etc.). Logran exteriorizarse en diversos modelos representacionales (estáticos o dinámicos, topológicos o geométricos, analógicos o cuantitativos, axiomáticos o exploratorios) así como manejar un número variado y variable de medidas (centralidad, intermediación, conectividad, cohesión, etc.).

$\checkmark$ Los ARS-SNA no son unilaterales, ni su acento es exclusivamente cuantitativo, las cifras no denotan posiciones absolutas de los objetos sino, más bien, relativas al interior de un mismo campo de atributos debidamente formalizado por el investigador. Constituyen una herramienta heurística flexible, adaptable y valiosa para el análisis de las interacciones e interconexiones sociohistóricas.

$\checkmark$ En los ARS-SNA la construcción de las matrices de datos, así como la información volcada en las mismas -problema fáctico de definición de interrelaciones analizablesremite necesariamente a una problemática epistémico de primer orden para el historiador posicionado en la utilización de los mismas como herramienta heurística. 
$\checkmark \quad$ Lo que determina la red, su forma y extensión, no es esencialmente el conjunto de los actores o agentes que ella comprende sino, más bien, el carácter que adquieren las interacciones entre unos y otros, expresadas en lo que podemos denominar matriz de contacto e interacciones, a partir de la particular estructura de unión que comprenden los grafos. Podemos afirmar entonces que es simplemente una abstraccióncondicionada y controladaque adquiere sentido en términos de la simplificación por parte del investigadorde la posibilidad de establecer los distintos agrupamientos de enlaces que cohesionan y extienden las redes.

$\checkmark$ Las redes adquieren así un tamaño y una densificación a partir del análisis de las interacciones compuestas en su interior. En este sentido los niveles de escala son absolutamente determinantes, tanto para el historiador como para el cientista social abocado en la utilización de estos modelos analíticos-representacionales, para definir la viabilidad heurística en la aplicación de los mismos. son modelos relativamente aceptables para pequeños mundos por razones matemáticamente obvias del manejo de los datos, pero empíricamente inexistentes.

La densificación de información es un elemento esencial que incorporar en el diseño de nuestros análisis ARS-SNA. La utilización de diversos tipos de documentación es fundamental para el desarrollo de una matriz de densificación relacional. En el espacio septentrional castellano tardo-medieval/temprano moderno los relatos genealógicos, las fuentes fiscales (siempre parciales), los elementos heráldicos (extendidos espacialmente), así como la genealogía son algunos de los elementos claves a la hora de densificar. El control de un espacio delimitado se presenta también como un elemento clave a la hora de construir estas matrices de relaciones inter-linajísticas densas.

\section{Notas}

(1) Merindad Menor de Vecio, cuya personalidad jurídico-administrativa se conoció entre los siglos XII al XIV, desapareciendo progresivamente de la documentación para la Edad Moderna. Englobaba los valles señoriales pertenecientes a la casa de los Velasco (Ruesga, Soba y Villaverde) así como los de realengo (Liendo y Guriezo), y las Juntas Reales de Sámano (Otañes, Mioño, Lusa, Ontón y Agüera) y Parayas, también las villas aforadas de Vizcaya (Limpias y Colindres), unidas a las villas realengas de Laredo y Castro Urdiales, y las villas interiores del valle de Mena.

(2) En este trabajo dichos términos son analíticamente equiparables, más no reducibles uno con otro.

(3) Para las problemáticas generales en terminología y conceptos para la Edad Media Iglesia Duarte, J. I. de la, (ed.). Memoria, mito y realidad en la historia medieval, Logroño, Instituto de Estudios Riojanos, 2003. Para el ámbito del reino de Castilla Fernández De Larrea, J. A., y Díaz De Durana, J. R.(eds.). Memoria e Historia. Utilización política en la Corona de Castilla al final de la Edad Media, Madrid, Silex, 2010 y Dacosta, A.; Prieto Lasa, J. R. y Díaz De Durana, J. R., (eds.). La conciencia de los antepasados. La construcción de la memoria de la nobleza en la Baja Edad Media, Madrid, Marcial Pons Historia, 2014.

(4) La llamada "lucha de bandos" no debe asumirse como un simple enfrentamiento bilateral entre bandos nobiliarios rivales, sino como un catalizador de un conjunto más amplio de conflictos sociales, con diferentes niveles de expresión. Según J. A. García de Cortazar, la 
misma debe ser analizada como un agregado de grupos sociales en pugna, así como una amplia tipología de conflictos. En su estudio el autor nos muestra concretamente tres tensiones generales: a) la que mantiene la nobleza rural con sus propios labradores (enmarcada en el espacio de la presión señorial producida por las dificultades rentísticas derivadas de la crisis del siglo XIV), b) la que enfrenta esta nobleza rural con la consolidación de los espacios urbanos y las nuevas realidades socioeconómicas que presentan las villas marítimas y, finalmente, c) la que termina siendo configurada por los propios linajes rurales en pugna entre sí. Es decir, tres marcos tipológicos diferenciales de violencia que se sustentan en una misma denominación al interior de un conflicto generalizado. Véase García De Cortazar, J., Á., "El fortalecimiento de la burguesía como grupo social dirigente de la sociedad vascongada a lo largo de la crisis de los siglos XIV y XV", en La sociedad vasca rural y urbana en el marco de la crisis de los siglos XIV y XV, II Simposio del Señorío de Vizcaya, Bilbao, Diputación Foral de Vizcaya, 1975, pp. 283-312.

(5) Los investigadores concuerdan en señalar tres grandes fases en que se desarrolla la "lucha de bandos" en estos territorios: una primera etapa, que se desarrolla entre mediados del siglo XIV a mediados del siglo XV, caracterizada por la violencia y competencia entre bandos. Una segunda etapa, que se extiende desde mediados del siglo XV hasta aproximadamente mediados de la década de los 70', menos conflictiva que la primera y caracterizada por el acuerdo alcanzado entre los linajes para repartirse pacíficamente el poder. Finalmente, una tercera etapa, que se extiende temporalmente desde 1475 hasta el año 1494, momento en el cual los Reyes Católicos ordenaron la desaparición de los bandos trasmeranos. Dicha resolución fue continuada con la Pragmática Real del 15 de marzo de 1501, en la cual los Reyes Católicos ordenan la total disolución de los "bandos linajes y parcialidades", no sólo en Cantabria, sino en los reinos de Galicia, el Principado de Asturias de Oviedo, así como en el Condado de Vizcaya, en la provincia de Guipúzcoa y en las Encartaciones.

(6) La bibliografía sobre linajes, bandos y parientes mayores en el espacio septentrional del reino de Castilla es amplia, aquí sólo podemos señalar algunas de ellas, por ejemplo: Achón Insausti, J. A. "A voz del concejo". Linaje y corporación urbana en la constitución de la provincia de Guipúzcoa: los Bañez y los Mondragón, siglos XIII al XVI, Diputación Foral de Guipúzcoa, 1995; Arocena Echeverría, I. "Los parientes mayores y la guerra de bandos en País Vasco", Historia del Pueblo Vasco I, San Sebastián, Erein, 1978, pp. 151-172; Díaz De Durana, J., R., (edit.). La lucha de bandos en País Vasco. Guipúzcoa: de los Parientes Mayores a la Provincia (siglos XIV al XVI), Bilbao, Servicio Editorial de la Universidad de País Vasco, 1998.

(7) La lógica que ordena el propio relato banderizo a su interior es la simple premisa que moviliza y da sentido a las acciones violentas emprendidas: "valer más..." expresión que no sólo nos remite al problema del "honor", sino también señala la sórdida lucha por intereses económicos y políticos que se encontraban ensamblados al interior de estas estructuras parentales amplias que son los linajes. Debemos tener en cuenta que tanto la promoción como el acrecentamiento de los distintos representantes de esta pequeña nobleza local y comarcal que disponían de sus parientes y clientelas para hacer valer su preponderancia, por la fuerza, a nivel local o regional- encontraba, en estas las alianzas circunstanciales de los "bandos linajes", su lógica de expresión y articulación.

(8) En comparación, los nobiliarios españoles tienen una difusión mucho más tardía debido a una evolución diferenciada de la nobleza en estos territorios. Los estudios antroponímicos revelaron que, en España, especialmente en Galicia y el norte, la conformación feudal de la nobleza fue más tardía. Algunos autores sostienen quela característica del espacio ibérico de frontera abierta con el islam permitía formas de promoción particulares en la península, sin necesidad de "desanclar", del reparto básicamente igualitario de la herencia, a las representantes del sexo femenino y a los segundogénitos. Otros autores sostienen una posición difusionista que entiende la expansión de un modelo familiar -se pasa de la familia amplia a la familia nuclear- y que ello determina que la herencia empiece a repartirse de otra manera a partir de una diferente concepción de las relaciones familiares.

(9) Sirva como ejemplos los trabajos clásicos de Duby, G. Hombres y estructuras de la Edad Media, Madrid, Siglo XXI de España editores, 1980 (1978), especialmente los capítulos 8 y 9; la obra colectiva dirigida por Nora, P. (dir.). Les lieux de mémoire, París, Gallimard, 4 tomos, (1984-1993); y el trabajo de Ruiz Doménech, J. E. La memoria de los feudales, Argot, Barcelona, 1984. Ambos libros tratan de la aparición de la genealogía, hasta entonces propia de los reyes, en la nobleza. 
(10) Beceiro Pita, I. "La legitimación del linaje a través de los ancestros", en Fernández De Larrea, J. A., y Díaz De Durana, J. R., (eds.). Memoria e Historia. Utilización política en la Corona de Castilla a fines de la Edad Media, Madrid, Sílex, 2010, pp. 77-100.

(11) Véase Clavero, B. Mayorazgo. Propiedad feudal en Castilla (1369-1836), Madrid, Siglo XXI, 1989.

(12) Libro de las Bienandanzas e fortunas, Libro XX. En Las Partidas, por ejemplo, se puede observar también que la definición corre por estas líneas argumentativas: (linaje) "Ayuntamiento de personas que se tienen unos de otras, como cadena, descendiendo de una rayz; e fazen entre si distintos grados departidos... La primera es una línea que sube arriba como padre o abuelo o bisabuelo... la otra que desciende: así como fijo o nieto... la otra es que viene de travieso. Esta comienza en los hermanos, e de si desciende por grado en los fijos." Partida IV, tít. VI, ley II.

(13) Lo más general es que las Behetrías fuesen señoríos colectivos, es decir, afectaban a localidades enteras (aunque también hubiese behetrías individuales). Los habitantes de esos pueblos podían elegir a su señor y pactar las condiciones del contrato (el señor ofrecía la protección y la superestructura organizativa, mientras que los labriegos pagaban ciertas prestaciones). El término behetría procede del latín "benefactoría" y, como afirma el medievalista Carlos Estepa Díez estaríamos en presencia de una institución que procede de una fase previa a la definitiva consolidación de las estructuras señoriales.

(14) "Este solar de Solórzano antiguamente era mayor de todos los Negretes e, el de Agüero, de los Giles; e trocáronse, ca el de Solórzano fue mayor de los Giles e el de Agüero fue mayor de los Negretes". García de Salazar, Lope, Bienandanzas y Fortunas, Libro XXI.

(15) $A R S=$ Análisis de Redes Sociales o SNA= Social Networks Analysis.

Recibido: agosto de 2017.

Aprobado: noviembre de 2017.

\section{Para citar este trabajo}

Pereyra, O. V. "Redes clientelares, agentes y dependientes en el espacio señorial castellano. Dinámica de articulación de linajes y elementos para su análisis" en Cuadernos de H Ideas [En línea], vol. 11, no 11, diciembre 2017, consultado...; URL: http://perio.unlp.edu.ar/ojs/index.php/cps/article/view/4543 